\title{
NONLINEAR CONTROL OF AN ISOLATED MOTION SYSTEM WITH DFIG
}

\author{
P. Caratozzolo*, E. Fossas`, J. Riera^ \\ "CENIDET, 62490 Cuernavaca, Morelos, Mexico \\ - IOC/Universitat Politècnica de Catalunya, 08028 Barcelona, Catalonia, Spain \\ “IRI /Universitat Politécnica de Catalunya-CSIC, 08034 Barcelona, Catalonia, Spain
}

\begin{abstract}
This paper investigates the design and implementation of different control schemes for a generation and motion system, which is characterized by the use of induction machines. Main applications are related with motion control in isolated power systems. Scalar control and feedback linearization control techniques of the motion system are presented. Computer simulation and experimental results confirm the validity of the control strategies developed in this work. Copyright (C) 2002 IFAC
\end{abstract}

Keywords: Electric power systems, induction machines, motion control, nonlinear control.

\section{INTRODUCTION}

In recent years more attention has been focused on induction machines for low and medium power generation because they have attractive advantages over conventional generators such as low unit cost, less maintenance, etc. Double-Fed Induction Generators (DFIG) are particularly suitable for isolated operation like in hydro and wind developments, even in cases where load is an AC motor (Tnani, et al., 1995) (Mebarki and Lipczynski, 1995).

This paper is based on the mathematical model for a specific isolated generation system that was presented by Caratozzolo, et al., (2000). That system, the Joint System (JS), considers a double-fed induction generator and an induction motor acting as a load. The main objective of such a system is to accurately control the motion of the output drive making use of the energy of a primary mechanical energy source. The mathematical model and some experimental results for a prototype system are presented in section 3 .

The power flow in this system and its different modes of operation are presented in section 4. In sections 5 classical scalar control techniques are applied to the system and, in addition, a feedback linearization control scheme is presented in section 6 . Simulink $^{\mathrm{TM}}$ simulation results are presented too.

\section{SYSTEM CONFIGURATION}

DFIG are used to convert mechanical power into electrical power operating near the synchronous speed with some advantages over the synchronous or squirrel cage generators. These advantages are the high overall efficiency of the system and the low power of the converter, which is in the rotor of the machine. Reactive power is produced exciting the rotor by an external power source (i.e. batteries). In isolated operation, the stator of the DFIG is connected to a load, in this case an induction motor (IM), obtaining a variable frequency/variable voltage system (VFVV).

Figure 1 shows the configuration of this system. If the DFIG is driven by a constant speed prime mover this generation scheme can be used for example in several autonomous generation plants.

With the prime mover running at constant speed, the performance of the primary energy source can be optimized. 


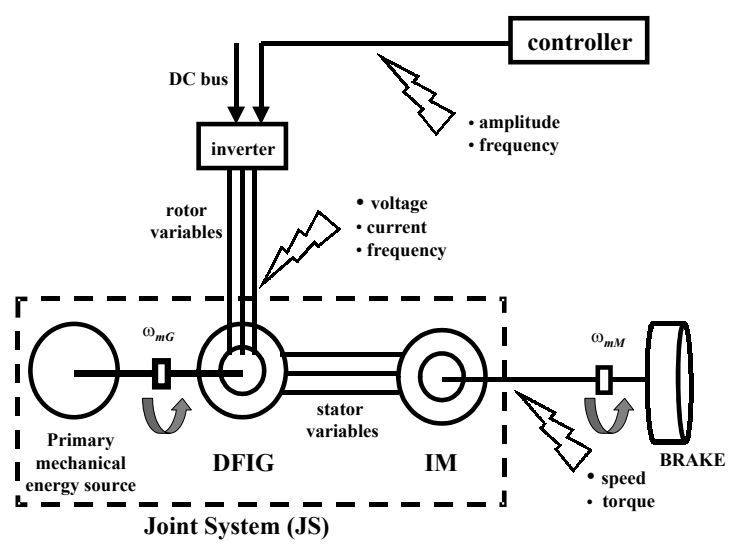

Figure 1. System Configuration

In this system the DFIG is able to operate in two modes: sub- and super-synchronous, delivering leading or lagging stator current to the motor. Depending on the operating condition, power may flow from the converter to the rotor or in the reverse direction (Alins et al., 1998). As the mechanical power delivered from the prime mover is normally larger than the electrical energy required from the converter at the rotor side, the control system has to be rated only for slip power, which is only a fraction of stator power. The resulting reduction in the converter costs makes this slip recovery system very attractive in all applications where energy saving is an important factor (Tnani, et al., 1995).

The behavior of the JS can be explained as follows: JS is an autonomous generation system that can drive a rotating load with mechanical speed $\omega_{m M}$ and torque $T_{M}$, delivering an output power $P_{m M}$ to the load. JS is feed by the prime mover, which can be an internal combustion motor or a gas turbine, depending on the type of isolated plant considered. Prime mover maintains a constant mechanical speed $\omega_{m G}=K$, where $K$ is chosen to optimize global performance. A bank of batteries is connected to the JS rotor circuit via a converter, delivering slip power $P_{r G}$, a fraction of total power.

The JS can operate in several modes of operation depending on the range of mechanical speed needed at the output. Specifically, for lower $\omega_{m M}$, JS can be forced to run in battery mode, where only slip power is used, the prime mover is at standstill and the DFIG is acting like a transformer. For intermediate speeds, Js is able to run in supersynchronous mode, which implies that prime mover is driving the DFIG with speed $K$ and the energy recovering flow allows to recharge the battery bank. Finally, for high speeds, JS is able to run in subsynchronous mode, using not only mechanical power delivered by the prime mover but also additional power that can be delivered by the battery bank.

Forcing JS to run in specific modes of operation allows that all power capability (mechanical and electrical) can be better used.

\section{MATHEMATICAL MODEL}

The model obtained in (Caratozzolo, et al., 2000) uses the voltage equations from the theory of induction machines with the following assumptions: balanced phase, linear magnetic conditions, unsaturated operation and symmetrical construction of the wound rotor (DFIG) and squirrel rotor (IM) machines.

Stator and rotor voltage equations for the induction machines, DFIG and IM, are derived and formulated in the synchronously rotating reference frame, because the speed $\omega_{s}$ is common to both stator currents. This reference frame is usually more convenient for small-signal dynamic stability analysis about some operating condition because it yields steady-state values of voltages and currents under balanced conditions (Vas, 1994). A Ku transformation, also called complex state Park's vector (Subrahmanyam and Subbarayudu, 1979) is used to refer the stator and rotor variables to the synchronous reference frame.

The JS model is obtained considering the models of the DFIG and the IM (to distinguish among the generator and motor variables, an additional $G$ or $M$ subscript is added):

$$
M_{1} \frac{d}{d t} x=-M_{2}(\omega) x+v
$$

where

$$
\begin{gathered}
M_{1}=\left(\begin{array}{ccc}
L_{G M} & M_{G} & -M_{M}^{c} \\
M_{G} & L_{r G} & 0 \\
0 & 0 & L_{r M}
\end{array}\right) \\
M_{2}=\left(\begin{array}{cccc}
r_{G M}+j \omega L_{G M} & j \omega M_{G} & -j \omega M_{M}^{c} \\
j g_{G} \omega M_{G} & r_{r G}+j g_{G} \omega & L_{r G} & 0 \\
r_{r M} & 0 & r_{r M}+j g_{M} \omega L_{M}
\end{array}\right) \\
x=\left(\begin{array}{lllll}
i_{s G} & i_{r G} & \left.i_{m M}\right)^{T} & v=\left(\begin{array}{llll}
0 & v_{r G} & 0
\end{array}\right)^{T}
\end{array}\right.
\end{gathered}
$$

and the equations of motion

$$
T_{G}-T_{\text {Gresist }}=J_{G} \frac{d \omega_{m G}}{d t} \quad T_{M}-T_{\text {Mload }}=J_{M} \frac{d \omega_{m M}}{d t}
$$

State variables $i_{S G}$ and $i_{r G}$ are the stator and rotor currents of the DFIG, and $i_{m M}$ is the magnetizing current of the IM. $T_{\text {Gresist }}$ is the externally applied mechanical torque from the prime mover, $T_{\text {Mload }}$ is the load torque at the IM shaft. The electromagnetic torques $T_{G}$ and $T_{M}$ can be expressed as follows:

$$
\begin{aligned}
& T_{G}=2 M_{G} \mathfrak{I} m\left(i_{s G} i_{r G}^{*}\right) \\
& T_{M}=2 M_{M}^{c} \mathfrak{I m}\left(i_{s M} i_{m M}^{*}\right)
\end{aligned}
$$

Finally, the plant can be modeled by a system of complex ordinary differential equations (1), and by two mechanical constrains, these later real, namely: 


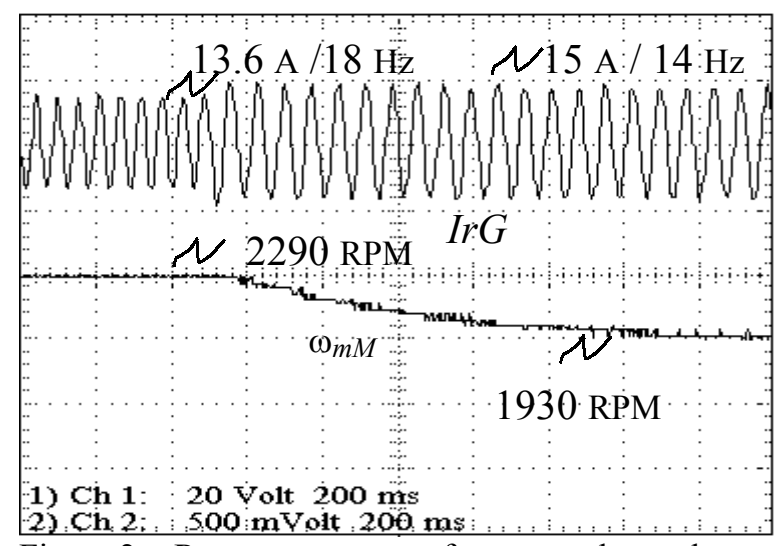

Figure 2 .- Response to a step frequency demand

$$
\begin{aligned}
& \frac{d \omega_{G}}{d t}=\frac{1}{J_{G}}\left(2 M_{G} \Im m\left(i_{s G} i_{r G}^{*}\right)-T_{\text {Gresist }}\right) \\
& \frac{d \omega_{M}}{d t}=\frac{1}{J_{M}}\left(-2 M_{M}^{c} \Im m\left(i_{s G} i_{m M}^{*}\right)-T_{\text {Mload }}\right)
\end{aligned}
$$

In order to validate the JS mathematical model, some experimental tests have already been conducted for different operating conditions. The hardware setup is composed by a PC host, a Texas Instrument TMS320C40 DSP system, a PWM amplifier and a 20 $\mathrm{KW}$ inverter. Also $\mathrm{A} / \mathrm{Ds}$ and $\mathrm{D} / \mathrm{As}$ with associated electronic interface boards and several JEULIN electric machines are used: a DC motor, a wound rotor induction motor, a squirrel cage induction motor and an electromagnetic brake. The machines parameters were identified using usual techniques and can be found in the APPENDIX.

Figure 2 represents the response of the $J S$ to a frequency change of the input voltage, $\omega_{r G}$, from $18 \mathrm{~Hz}$ to $14 \mathrm{~Hz}$; the amplitude of the input signal was maintained at $25 \mathrm{~V}$. The drop in the output mechanical speed $\omega_{m M}$, is $360 \mathrm{RPM}$ and the rotor input current presented an amplitude rise of 1.4A.

Figure 3 shows the $J S$ response to an amplitude step of the input voltage $V_{r G}$, maintaining the input frequency at $18 \mathrm{~Hz}$. A change from $14 \mathrm{~V}$ to $25 \mathrm{~V}$ in $V r G$ produces a rise of 7.3A in $I_{r G}$, and a speed drop of 150RPM in $\omega_{m M}$.

\section{POWER FLOW CONSIDERATIONS}

The main objective of the Joint System shown in Figure 1, is to generate torque $T_{M}$ and control mechanical speed $\omega_{m M}$, using its energy resources in the best way. The operation mode chosen for the JS to work depends on the speed level demanded $\omega_{m M r}$ for the load connected to the motor shaft. In this way, it can be established two operation modes: the normal mode, or electromechanical mode, and the battery mode.

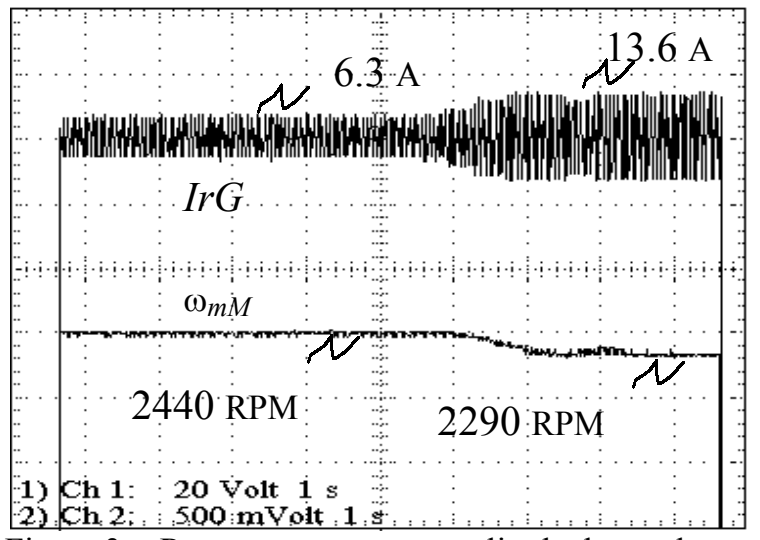

Figure 3 .- Response to a step amplitude demand

Normal mode. The wound rotor induction machine is acting like a DFIG; the prime mover speed $\omega_{m G}$, is held constant; the power drawn from the converter at the rotor side, named slip power, is derived from the batteries. This operation mode includes two operation submodes:

Subsynchronous mode. The DFIG is working at subsynchronous speed, so generator slip has positive value, $g_{G}>0$. The driving power to the DFIG from the prime mover is $P_{m G}$, then the mechanical input power $P_{g G}=P_{m G}-P_{l m G}$, where $P_{l m G}$ are the rotational losses of the generator. The power transmitted to the air-gap, $P_{a g G}$, is greater than the mechanical input power obtained from the prime mover. This is because the secondary source is providing a slip power, $g_{G} \cdot P_{a g G}$, from the batteries. Total rotor losses $P_{l r G}$ indicates the losses in the total rotor resistance $r r$, that in a wound-rotor machine also includes any external resistance and the converter. $P_{r G}$, in turn, is the power provided by the battery. The output power into the motor is therefore $P_{s G}=P_{a g G} P_{l s G}$, where $P_{l s G}$ are the stator losses. The maximum power available at the output is the sum of $P_{a g G}$ and $g_{G} \cdot P_{a g G}$, $\left(1+g_{G}\right) \cdot P_{a g G}$, minus the losses in each step of energy conversion.

Supersynchronous mode. The DFIG is working at supersynchronous speed, so $g_{G}<0$ is verified. The losses presented in the machine are the same that was indicated for the subsynchronous mode. The power crossing the air-gap, $P_{a g G}$, is less than the mechanical input power obtained from the prime mover. The excess power $g_{G} P_{a g G}$ is returned to the secondary circuit to provide recharging power to the batteries.

Battery mode. The DFIG is at standstill, so $g_{G}=1$, the prime mover speed $\omega_{m G}$, is zero, thereby DFIG is behaving like a transformer system. The power crossing the air-gap is only the power delivered by the batteries. Obviously, the maximum power available at the output is the battery power minus the losses in each step of energy conversion.

In figure 4 power flow in the JS is illustrated for both operation modes (normal mode and battery mode). 


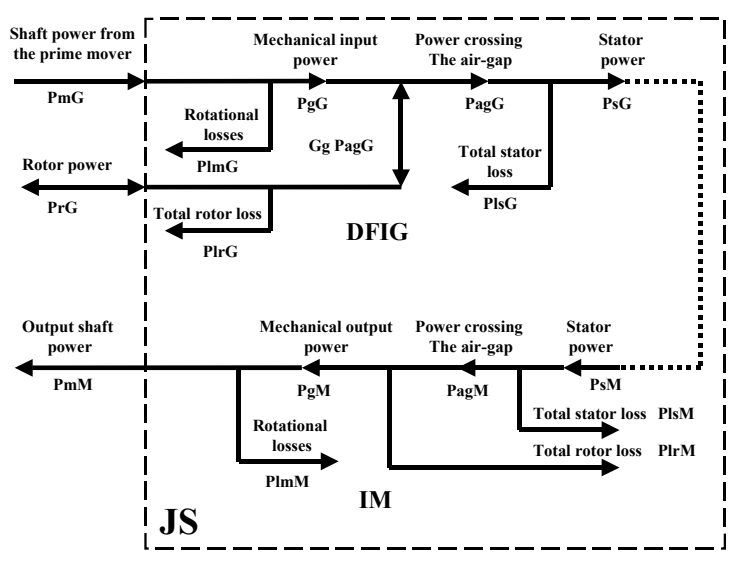

Figure 4. Power flow in the DFIG and the IM.

Double arrow for $P_{r G}$ indicates the dual possibility to provide or return power from/to the battery in subsynchronous mode and supersynchronous mode respectively. A fully defined speed range of operation is presented in figure 5. Due to the fact that input speed $\omega_{m G}$ is constant, speed limits instead of power limits are used in order to establish the ranges of operation. It can be seen that JS can be operated in normal mode in a speed range of $0<\omega_{m M}<\omega_{m M}$ MAX if high levels of output power $P_{m M}$ are required. However, there is the possibility of battery operation in a speed range of $0<\omega_{m M}<\omega_{m M B A T}$ if demanded output power does not exceeds the power capability of the battery.

\section{SCALAR CONTROL TECHNIQUES}

Scalar frequency control offers the advantage of simple operation, but provides limited speed accuracy and poor torque response because the torque and flux are indirectly controlled. Control is provided by a frequency and voltage reference generator with constant volts per hertz output which drives an inverter.

With an inverter supply, the magnitude, frequency, and phase of the voltage applied to the Joint System can all be varied electronically. It can also be seen that the torque can be controlled by adjusting stator flux, slip speed or both, via the control of the JS's rotor voltage magnitude and frequency. Within the voltage rating of the inverter, the magnitude of the rotor voltage can be adjusted to keep stator flux constant. Rotor excitation flux may be considered as the product of stator excitation flux and slip.

Thus, over a constant torque range, maintaining rotor flux at a level capable of providing the maximum expected torque is preferred. Above base speed, slip speed is held constant by allowing slip to increase with speed until it reaches its maximum, $g_{\text {MmaxT }}$. In the Volts/Hertz, $\mathrm{V} / \mathrm{H}$, scheme shown in figure 6 , the mechanical speed command signal $\omega_{m M r}$ is compared with the measured rotor speed $\omega_{m M}$ to generate an error signal that feeds the speed controller.

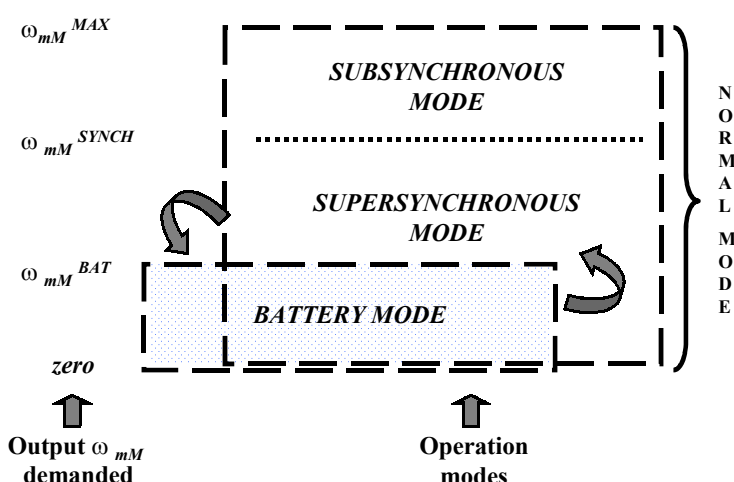

Figure 5. Speed range for each operation mode.

The speed controller is of PI type, thus speed error is transformed into torque reference through the PI transfer function $G_{P I}=K_{P I}\left[1+1 / T_{P I} p\right]$, where $K_{P I}$ is the controller gain, and $T_{P I}$ is the controller integral time constant, both determined to avoid commutation failures when the speed error is high.

The slip limiter block is obtained linearizing the "torque/slip" curve of the JS and the limitation in torque comes from the expression of maximum torque. This block generates the output signal $\omega_{\text {slip }}$ which directly determines the inverter frequency $\omega_{r}$.

At the same time, the frequency command defines the rotor amplitude command $\left|V_{r}\right|$ through the block flux control. This block is represented by a function transference, $V r / \omega_{r}=j L_{r d G} \operatorname{Ir} G+M_{G} I_{m G}$ analytically determined from the JS steady-state model.

In this way the voltage across the rotor terminals is adjusted to the frequency retaining an approximately constant rotor flux. In the low frequency range, compensation of the rotor resistance voltage drop may be added to the voltage command signal.

With a controlled slip strategy the power factor and the torque-to-rotor current ratio can both be kept high. This results in a better utilization of the available inverter current (Ong, 1998).

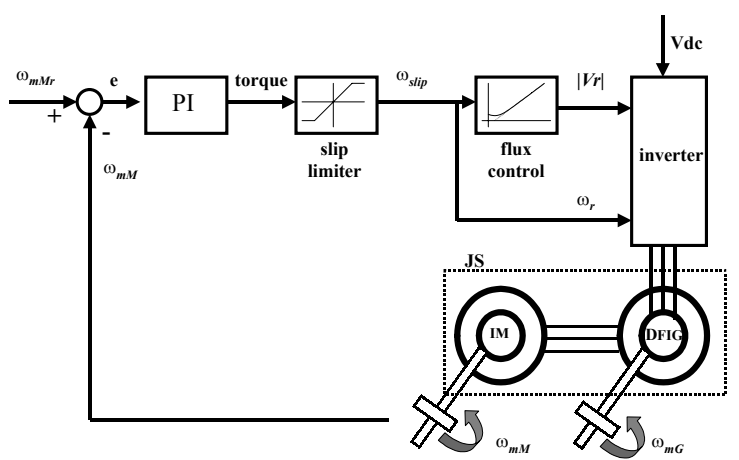

Figure 6. Speed control with constant $\mathrm{V} / \mathrm{H}$ and slip regulation. 

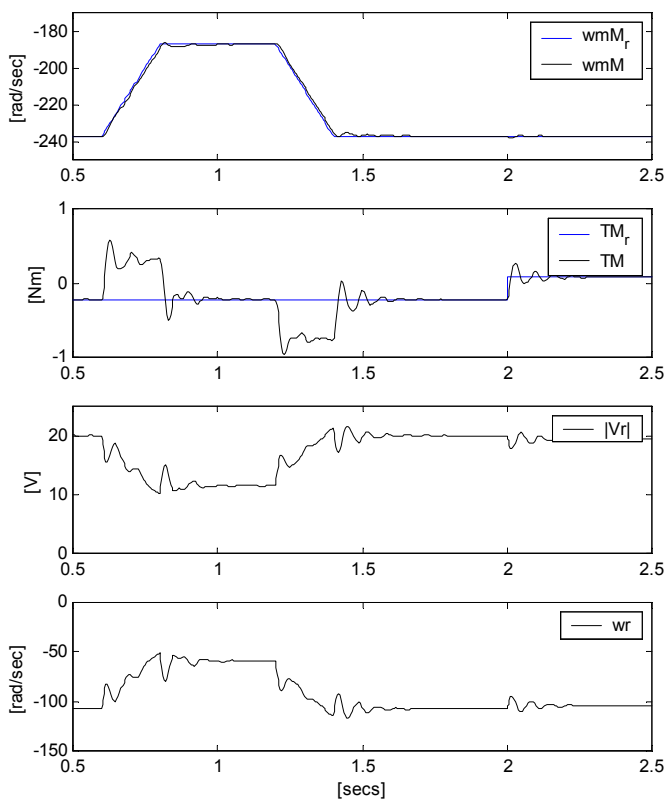

Figure 7. Speed tracking of the JS with a scalar control scheme.

In scalar motor control, the control objective was usually motor speed, thus JS behavior with constant $\mathrm{V} / \mathrm{H}$ is shown in figure 7 . In the figure the speed reference follows a ramp signal with changing slopes at instants $0.6,0.7$, and 1.4, with a step increase in the mechanical load at instant 2.0 secs. Also control efforts $|V r|$ and $\omega_{r}$ are shown in the same figure.

\section{FEEDBACK LINEARIZATION CONTROL TECHNIQUES}

A characteristic feature of modern control is that the controlled output is motor torque. The motor is included in the closed loop of modern control, and, even if the control objective is speed, the motor is controlled with respect to its shaft torque (Yamamura, 1992).

As it can be easily checked, the system is not linearizable by state-feedback. However, in case the interest focuses on controlling the mechanical torque, control laws providing an input-output linear behaviour can be obtained.

The derivative of the IM mechanical torque can be put in the following form

$$
\begin{aligned}
\frac{d}{d t} T_{M}=-\alpha T_{M} & +x_{5}\left(\beta_{1}+\beta_{2} u_{2}\right) \\
& +x_{6}\left(\delta_{1}+\delta_{2} u_{1}\right)
\end{aligned}
$$

where the nonlinear terms in the mechanical torque are factorised by $x_{5}$ and $x_{6}$, that are the real and complex components of the state variable $i_{m M}$.

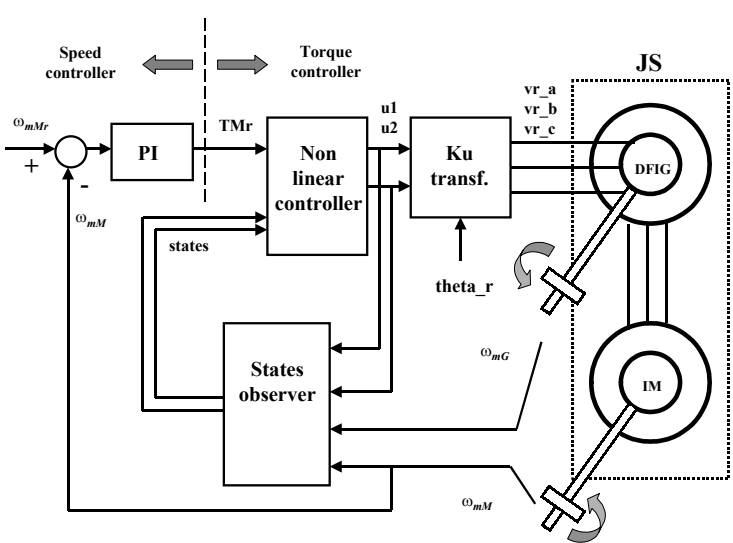

Figure 8. Nonlinear control configuration of the JS.

Equation (5) results in

$$
\frac{d}{d t} T_{M}=-\alpha T_{M}+\left(x_{5}^{2}+x_{6}^{2}\right) v
$$

Finally, the substitution $\hat{v}=\left(x_{5}^{2}+x_{6}^{2}\right) v$ in the latest equation yields

$$
\frac{d}{d t} T_{M}=-\alpha T_{M}+\hat{v}
$$

Figure 8 shows the resulting block diagram that implements this control strategy. A second control loop can be easily added to transform the torque controller into a speed controller. Although this controller requires all the system states, only $\omega_{m G}$ and $\omega_{m M}$ are measured. Currents $i_{s G}, i_{r G}$ and $i_{m M}$ are obtained by means of an observer which makes use of equation (1) and (6) considering that $u_{1}, u_{2}, \omega_{m G}$ and $\omega_{m M}$ are known.

The dynamic behavior of the torque control system is shown in figure 9, where the first order dynamics and zero steady-state error can be observed. Note, also, that the response is very fast while control signal, $\mathrm{Vr}$, remains small. If the system has to track a speed reference signal, it also shows a good performance and a quite smooth dynamic response as can be seen in figure 10.

\section{CONCLUSIONS}

The motion system that is presented obtains the energy from a primary mechanical source. The DFIG allows to transform this energy but also to control the torque or speed of the induction motor making use of the rotor voltage as control variable. Two kinds of controllers have been designed to improve the system's behaviour. A quite simple scalar control technique shows that the speed of the Joint System can be controlled in an effective way. A nonlinear control, based in state feedback, allows to obtain output torque very accurately with a predefined first order dynamics. The states are being approximated by an observer. 

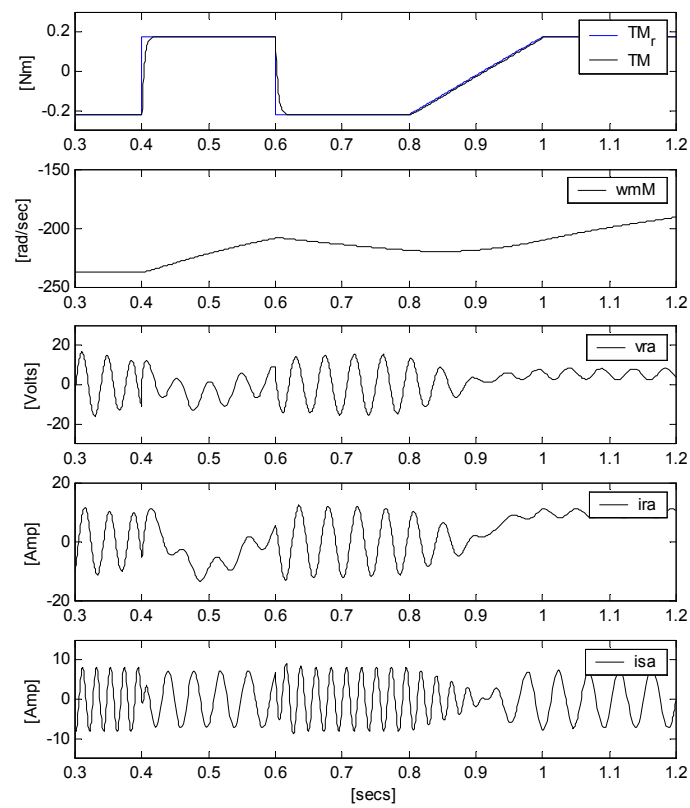

Figure 9. Torque tracking using the nonlinear control scheme.

Power flow considerations have been introduced, suggesting different modes of operation that allow energy savings and power capability improvement.

\section{REFERENCES}

Alins, J., P. Caratozzolo, J. Riera (1998). New Model of a Double-Fed Induction Generator as Voltage \& Frequency Converter, Proceedings of the CONIELECOMP'98, Universidad de la Américas-Puebla, México.

Caratozzolo, P., E. Fossas., J. Pedra, J. Riera (2000) Dynamic Modeling of an Isolated Motion System with DFIG. Proceedings of the CIEP'O0, Acapulco, Mexico.

Mebarki, A. and R. Lipczynski (1995). A Novel Variable Speed Constant Frequency Generation System with Voltage Regulation, Proceedings of EPE'95, Sevilla, Spain, pp.2465-2471.

Ong, C. (1998). Dynamic Simulation of Electric Machines, Chapters 6-9, (Prentice Hall, Ed.), New Jersey.

Subrahmanyam B. and D. Subbarayudu (1979). Steady-state analysis of an induction motor fed from a current-source inverter using complexstate (Park's) vector. Proceedings of the. IEE, Vol 126, No 5, May 1979, pp.421-425

Tnani, S., S. Diop, S. Jones, A. Berthon (1995). Novel Control Strategy of Double-Fed Induction Machines, Proceedings of EPE'95, Sevilla, Spain, pp.1553--1558.

Vas, P. (1994). Vector Control of AC Machines, Chapter 4, (Oxford Publications, Ed.), New York.
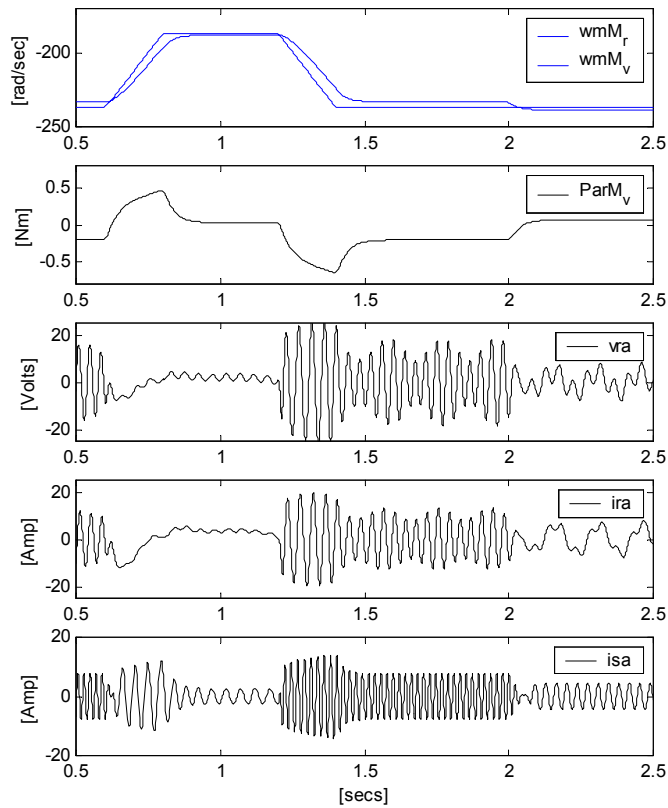

Figure 10. Speed tracking and regulation using the nonlinear control scheme.

Yamamura, S. (1992). Spiral Vector Theory of $A C$ Circuits and Machines, Chapter 2, (Clarendon Press, Ed.), New York.

\section{ACKNOWLEDGMENTS}

This work has been partially supported by the Spanish CICYT DPI2000-1509-C03-02, and the Bilateral Co-operation Program CONACYT - CSIC E130.1128/2001, Mexico-Spain.

\section{APPENDIX}

The rating of the induction machines and the prime mover dc are:

a) Prime mover separately dc motor

Output power, $200 \mathrm{~W}$

Ra, 1.27 ohms

Poles, 2

La, $12.94 \mathrm{mH}$

Armature current /

J, $1.565 \mathrm{Nms} 2 / \mathrm{rad}$

voltage, $9.2 \mathrm{~A} / 42 \mathrm{~V}$

Excitation current /

voltage, $0.35 \mathrm{~A} / 35 \mathrm{~V}$

Rotor speed, 3000 RPM

b) Wound rotor induction machine

Output power, $200 \mathrm{~W} \quad \mathrm{Rs}, 0.365 \mathrm{ohms}$

Poles, $2 \quad \mathrm{Rr}, 0.559 \mathrm{ohms}$

Nominal current, $10.4 / 6 \mathrm{~A} \quad$ Lsd, $0.938 \mathrm{mH}$

Nominal voltage, $24 / 42 \mathrm{~V} \quad$ Lrd, $0.938 \mathrm{mH}$

Rotor speed, 2800 RPM M, $12.975 \mathrm{mH}$

Frequency, $50 \mathrm{~Hz} \quad \mathrm{~J}, 4.358 \mathrm{e}-3 \mathrm{Nms} 2 / \mathrm{rad}$

c) Squirrel cage induction machine

Output power, $200 \mathrm{~W} \quad \mathrm{Rs}, 0.50 \mathrm{ohms}$

Poles, $2 \quad \mathrm{Rr}, 0.20 \mathrm{ohms}$

Nominal current, 10.4/6 A Lsd, $1.20 \mathrm{mH}$

Nominal voltage, $42 / 24 \mathrm{~V} \quad$ Lrd, $1.20 \mathrm{mH}$

Rotor speed, 2750 RPM M, $9.00 \mathrm{mH}$

Frequency, $50 \mathrm{~Hz} \quad \mathrm{~J}, 0.0011 \mathrm{Nms} 2 / \mathrm{rad}$ 